\title{
Dançando-Investigando a Arquitetura de Zaha Hadid Sob uma Perspectiva Coreológica
}

\author{
Cláudio Marcelo Carneiro Leão Lacerda \\ Universidade Federal de Pernambuco - UFPE, Recife/PE, Brasil \\ E-mail: claudiolacerda@hotmail.com
}

\section{Resumo}

Este artigo expõe a pesquisa-criação em dança inspirada pela obra da arquiteta iraquiana-britânica Zaha Hadid, com enfoque na perspectiva coreológica a partir da qual a mesma se desenvolveu. Teve como base teorias de Rudolf Laban, em interligação com os autores Gaston Bachelard e Maxine Sheets-Johnstone, informando os conceitos de imaginação espacial, imaginação corporal e imaginação de movimento. A pesquisa seguiu a abordagem metodológica da Prática como Pesquisa, valorizando o protagonismo do corpo dançante criativo e favorecendo trânsitos dialógicos verticais - corpo-intelectualidade, prática-teoria, criação-crítica - e transversais - entre os campos dos Estudos Coreológicos, estudos da dança, arquitetura, filosofia e artes visuais. Assim, objetivou-se valorizar o campo da dança como articulador de relações interartísticas e interdisciplinares. São descritos e discutidos o processo de materialização no corpo dançante da inspiração inicial por obras de Hadid, a dinâmica espiralada da pesquisa na figura do Anel de Moebius, as interrelações transversais entre os elementos da pesquisa e a processualidade e os desdobramentos da dança-investigação.
This article exposes the research-creation in dance inspired by the oeuvre of Iraqi-British architect Zaha Hadid, with a focus on the choreological perspective from which the research developed. It had as base theories by Rudolf Laban, interlinked with authors Gaston Bachelard and Maxine Sheets-Johnstone, informing the concepts of spatial imagination, bodily imagination and movement imagination. The research followed the methodological approach of Practice as Research, valuing the protagonism of the creative dancing body and fostering dialogical transits both vertical - body-intellectuality, practice-theory, creation-critique - and transversal - among the fields of Choreological Studies, dance studies, architecture, philosophy, and visual arts. Thus, it aimed to value the dance field as articulator of interartistic and interdisciplinary relationships. It is described and discussed the process of materialization in the dancing body of the initial inspiration by works by Hadid, the spiraled dynamics of the research in the figure of the Moebius Strip, the transversal interrelations among the elements of the research, and the processuality and the unfoldings of the dance-investigation.
Dance. Architecture. Choreography. Creative Process. Practice as Research. 


\section{Introdução}

Neste artigo descrevo e reflito sobre a criação-investigação em dança inspirada pela obra da arquiteta iraquiana-britânica Zaha Hadid (Bagdá 1950-Miami 2016), desenvolvida ao longo do Doutorado em Artes Cênicas realizado na Universidade Federal da Bahia (2014-2018), com período Sandwich na Coventry University (RU), e que gerou desdobramentos posteriores. A pesquisa de doutorado objetivou desenvolver uma coreotese (a aglutinação do prefixo coreo à palavra tese enfatiza o papel central do corpo dançante criativo - coreo tanto se referindo a coreografia quanto Coreologia - na pesquisa e na escrita), tendo como ponto de partida e inspiração a obra de Hadid para a criação em dança ${ }^{1}$, a partir de uma perspectiva coreológica. Teorias de Rudolf Laban constituíram a principal âncora para trabalhar com os conceitos de imaginação espacial, imaginação corporal e imaginação de movimento, no nível do devaneio e das transformações, através da interligação a outros autores, principalmente, Gaston Bachelard e Maxine Sheets-Johnstone, e da interrelação entre os campos disciplinares da dança, arquitetura, filosofia e artes visuais. A abordagem metodológica utilizada foi a Prática como Pesquisa $(P a R)$, que coloca o fazer artístico como o motor da mesma. Neste caso, o motor foi a investigação-criação coreográfica intitulada Contraespaço.

Apresentarei uma síntese das relações postas em movimento no Anel de Moebius da pesquisa. Inicio expondo os caminhos através dos quais a inspiração pela obra de Hadid foi encontrando sua materialização no corpo e na dança. Em seguida, apresento as teorias de Laban fundantes para a pesquisa e as interligações com teorias de Bachelard e Sheets-Johnstone. Posteriormente, descrevo e reflito sobre a processualidade de Contraespaço e os desdobramentos que advieram.

Minha posição político-acadêmica foi valorizar o campo da dança como articulador de rela-

1 Tese disponível no Repositório Institucional da UFBA: http://repositorio.ufba.br/ri/handle/ri/25534. ções interartísticas e interdisciplinares, o que se refletiu na escolha pela perspectiva coreológica, na adoção da $P a R$ e em colocar o corpo dançante criativo como locus privilegiado da pesquisa, com poder de articular seus elementos.

\section{Materializando no corpo e na dança a inspiração pela obra de hadid}

Minha experiência sensível quando visualizo obras de Hadid $^{2}$ - prédios, móveis, objetos de design -, em imagens e em visitas in loco, é de uma série de encadeamentos no âmbito das sensações: descentramento; fluxos de energia; não um caos, mas um ordenamento com uma lógica própria. Esses encadeamentos reverberam diretamente no meu corpo e provocam ímpetos de me mover a partir deles. Uma série de "intenções internas", usando uma expressão labaniana, começam a fermentar possibilidades de "manifestações externas". Esses estímulos deram a partida para criar-pesquisar dança.

Assim, iniciei um percurso motivado por conhecer o corpus de criações e projetos da arquiteta, seus processos criativos, modos de trabalho e referências. Pude perceber que as correlações que se podem fazer entre sua arquitetura e a dança são diversas e instigadoras. Primeiro, me chama a atenção, apesar da diversidade das obras e das diferentes fases criativas da arquiteta, uma qualidade de organicidade, remetendo a seres da natureza, como moluscos, larvas e vegetais, e características parciais de seres vivos, por exemplo, canais que se abrem em grandes espaços vazados, cujas fronteiras são indeterminadas. Encontrei uma grande facilidade em estabelecer analogias com o corpo, humano e não humano, como, por exemplo, nos trânsitos entre espaço interno e externo, nas várias camadas que compõem certas obras, na fluidez suscitada por certas formas e suas intercomunicações. Segundo, muitas vezes, a visão das obras dá a sensação de

2 Convido o/a leitor/a a visualizar obras projetadas por Hadid e Associados na internet. Sugiro o website da Zaha Hadid Architects: www.zaha-hadid.com. 
estarem em movimento e encadeia impulsos para me mover, a partir de, por exemplo, uma determinada torção, achatamento, alongamento ou projeção no espaço. Terceiro, as imagens dessas obras suscitam devaneios de habitar seus respectivos espaços.

Identifiquei-me com o forte papel da experimentação na trajetória de Hadid, o empenho em desenvolver sua própria linguagem arquitetônica, em tomar limitações como estimuladoras para o trabalho, a relação especial com o chão, brincadeiras com noções que se relacionam a espaço, estar consciente do ponto em que cada uma de suas referências deu algum tipo de ignição e ter isso como a própria ignição do processo criativo.

Retracei suas influências formativas principais nas artes visuais: os artistas russos modernistas Kazimir Malevich e Wassily Kandinsky. Inspirar-se nesses artistas significou voltar a uma fonte original que, segundo ela, havia inspirado a arquitetura moderna e continuar seu projeto não finalizado, no espírito experimental da vanguarda inicial. Seu fascínio por Malevich teve tal magnitude a ponto de Hadid tomar a pintura como ferramenta de trabalho, propondo-se a radicalizar a fragmentação e o ordenamento em camadas, técnicas composicionais dessa vanguarda inicial moderna, porém visando à realidade arquitetural e à vida real (HADID, 2004).

A caligrafia árabe também foi uma forte influência, refletindo-se nas curvas radicais de muitas obras. Esteve em sua formação escolar e criação em Bagdá, mas também havia sido inspiração para Malevich e Kandinsky, influenciando-a oblíqua e duplamente.

A fim de materializar corporalmente minha inspiração por Hadid, propus trabalhar com a imaginação espacial, a imaginação corporal e a imaginação de movimento, no nível do devaneio e das transformações. Minha intenção não foi "traduzir" sua obra para a dança, reproduzindo suas formas ou necessariamente tornando reconhecíveis características suas na dança criada. Quis reagir/responder às forças em sua obra, entrar no nível de devaneio que elas me suscitam e deixar a experiência da dança fluir, sem resultados pré-definidos.
Essa diretriz se coaduna à Prática como Pesquisa, que coloca o fazer artístico como o motor da mesma, conduzindo o processo, dando-lhe uma organicidade, uma característica de estar sempre em transformação (HASEMAN, 2006; PAKES, 2003; BONENFENT, 2012). Segundo Haseman (2006, p. 3), "Pesquisadores guiados pela prática constroem pontos de partida experimentais a partir dos quais a prática segue. Eles tendem a 'merguIhar', a começar praticando, para ver o que emerge".

Para robustecer os conceitos de imaginação espacial, corporal e de movimento, procurei âncora, principalmente, em Rudolf Laban, conferindo uma perspectiva coreológica à pesquisa. E coloquei-o em conversação com Gaston Bachelard e Maxine Sheets-Johnstone, formando uma interessante interligação. De Laban utilizei, especificamente, os conceitos de perspectiva corporal, imaginação espacial e labilidade e, mais abrangentemente, o conteúdo presente nas estruturas Corpo, Espaço, Dinâmica, Relações e Ações; de Bachelard, a valorização da imagem e da imaginação e os sentidos subjetivo e fenomenológico do habitar; de Sheets-Johnstone, suas noções de valorização da experiência, o corpo em primeira pessoa, o pensar em movimento, inteligência cinética e cinestésica das formas animadas e sensibilidade de superfície. Em um plano de fundo (aqui mencionados breve e superficialmente), utilizei conceitos de Jacques Derrida, trabalhados em pesquisas anteriores, como desconstrução, centro faltante, labilidade, espaçamento e "diferência", e de Gilles Deleuze, como mediadores e forças.

\section{Ativando o Anel de Moebius da pesquisa: Laban em diálogos}

Revisitei a trajetória formativa de Laban, por ser um dos autores motrizes da pesquisa e também porque, assim como havia retraçado as influências formativas de Hadid, quis, em paralelo, revisitar e expor as minhas, das quais Laban é uma das principais, tendo sido uma das mais fortes influências em meu trabalho como bailarino, coreógrafo, docente e 
pesquisador, especialmente pelos estudos de especialização realizados no Laban Centre em Londres (1997-1999) ${ }^{3}$. Isso possibilitou tecer várias relações entre dança e arquitetura e entre Laban e Hadid. Um fato marcante que redescobri é a formação de Laban, em sua juventude, em arquitetura e artes plásticas (PRESTON-DUNLOP, 1998b), embora não finalizada, o que influenciou, sem dúvida, o conteúdo da Coreologia, especialmente a Corêutica. Posteriormente, teci uma rede de conexões entre Laban, Malevich e Kandinsky, artistas-teóricos visionários que fizeram da ligação entre arte e espiritualidade o propulsor de suas inovações artísticas e teóricas. Também detectei a influência da caligrafia árabe para Laban (2011), a qual constituiu material de meditação para a criação da noção de trace forms.

Laban exerceu um trânsito entre polaridades. A ideia de um espaço ativo, cujos agentes são simultaneamente formativos e deformativos, foi um forte estimulador para o processo de Contraespaço. Formação e deformação, transformação e dissolução de polaridades encontram uma representação imagética perfeita no Anel de Moebius, que Laban utilizou sob o termo Lemniscate (LABAN, 2011, p. 85). Coloquei o Anel de Moebius na pesquisa como uma rede de fluxos onde interligações, interrelações e transversalidades pudessem acontecer.

A seguir, apresentarei os conceitos mencionados de Laban, Sheets-Johnstone e Bachelard.

O conceito de perspectiva corporal [bodily perspective] é a premissa a partir da qual toda a experiência em dança proposta por Laban, e a teoria advinda desta, se desenrola e tem por base a experiência do agente que a executa, produz e vivencia:

[...] a impressão do homem das formas, quando o poder motivador trabalha interiormente no corpo, é completamente diferente daquela recebida quando ele as olha de um ponto de vista exterior. Podemos chamar a visão a partir do interior de "perspectiva corporal". (LABAN, 2011, p. 85).

3 Professional Diploma in Dance Studies (1998) e Independent Study Programme Certificate (1999).
Esse conceito é de extrema relevância para reivindicar a importância da sabedoria do corpo, do conhecimento desenvolvido no e através do corpo, e, mais especificamente, da pesquisa em dança, realizada no contexto da academia, e da autonomia do campo da dança para agenciar relações interdisciplinares. A perspectiva corporal é um elo poderoso para efetivar a $P a R$ na área da dança.

Laban (1978) considera a labilidade como o estado ou condição em que falta (ou se procura) o equilíbrio. O estado de ser lábil é tratado em Domínio do Movimento ${ }^{4}$. Apesar de a estabilidade ser o que a maioria de nós almeja, a labilidade é importante porque nos desestrutura e, assim, faz com que nos ajustemos e nos transformemos em direção ao alcance do equilíbrio. Desde que conheci obras e arquitetos ligados à arquitetura desconstrutivista $^{5}$, vertente pela qual Hadid, entre outros arquitetos, ficou inicialmente conhecida, tenho percebido que o estado de labilidade permeia várias obras arquitetônicas ligadas a essa vertente. Creio que daí me veio a impressão de estarem em movimento.

Já Derrida utiliza o termo labilidade para um conceito filosófico, configurando-o como um lugar secreto que não é nem construção nem ruína:

O espaço de tensão entre polaridades é um espaço que precisa ser habitado. Um espaço de adiamento, de labilidade, de desestabilização, de devir, que não é valorizado pela filosofia e pela cultura ocidentais, justamente porque estas têm se baseado nessas polaridades [...] para se produzir. (DERRIDA, 2006, p. 66).

$4 \mathrm{Na}$ versão em português (1978), foi traduzido como "equilíbrio instável".

5 Expressão disseminada a partir da exposição Deconstructivist Architecture (MoMA, Nova York, 1988), com curadoria de Philip Johnson e Mark Wigley. Estes identificaram nos arquitetos expostos Frank Gehry, Daniel Libeskind, Rem Koolhaas, Peter Eisenman, Zaha Hadid, a cooperativa Coop Himmelblau e Bernard Tschumi similaridades formais com o construtivismo russo da segunda e terceira décadas do século XX e a vanguarda artística russa daquela época, de Malevich a El Lissitzky. A abordagem desconstrutivista não se restringe a esses arquitetos, tendo sido um recorte da exposição. (JOHNSON; WIGLEY, 1988) 
Trânsito e espaço de tensão entre polaridades e desestabilização põem em relação os pensamentos derridiano e labaniano, no que concerne à labilidade.

A imaginação espacial é definida por Preston-Dunlop como: "É uma questão de estar apto a imaginar [to envisage] um itinerário, antes que ele realmente aconteça, e criar com aquela visão. Isto é imaginação espacial." (PRESTON-DUNLOP, 1998a, p. 125). Está relacionada não só a itinerários e eventos futuros, mas também passados, que permanecem como rastros de memória, e ao próprio presente, na atualização do movimento. Aplica-se não só à pessoa que se move, mas também àquela que assiste $\mathrm{a}$, que testemunha, o movimento.

Nas noções de espaço presentes na Corêutica, nas escalas espaciais, Laban sugere que estas podem ser executadas em trajetórias lineares ou curvas e também em percursos centrais, transversos e periféricos (LABAN, 2011; FERNANDES, 2006). Por sua vez, Hadid procura brincar com as próprias noções que se relacionam a espaço. Por exemplo, a noção de canto [corner]: "Sempre estive interessada na noção de um assento para um anticanto [anticorner]. Cantos não precisam ser ângulos retos; eles podem ser muito mais fluidos, como curvas." (HADID apud BOYARSKY, 2008, p. 49). Isso vai ao encontro do jogo entre polaridades presente nos estudos labanianos, a compreensão e vivência de um espaço que é dinâmico entre dois pontos e além deles. Subverter e transformar o espaço são movimentos em ação na arquitetura e na dança contemporâneas.

Coloquei Sheets-Johnstone e Bachelard em relação com Laban, o que surtiu uma frutífera interligação, especialmente para minha busca de alimento teórico para a imaginação espacial, corporal e de movimento.

Sheets-Johnstone é uma filósofa da dança e artista de dança que construiu uma rica rede de pensamento na qual valoriza não só a dança, mas, antes disso, a experiência como fonte fundante do conhecimento, o pensar em movimento, o corpo em primeira pessoa, e uma sabedoria corporal cinética e cinestésica das formas animadas (i. e., todas as formas vivas). A reivindicação de Sheets-Johns- tone é mais profunda e anterior à dança; ela exige que as ciências reconheçam algo que ela identifica como velado, ou seja, o conhecimento corporal, cinético e cinestésico, que faz o reconhecimento do mundo em volta, que é anterior à linguagem (não é por ela mediado) e integrador de polaridades.

Em Sheets-Johnstone há um esforço sempre presente de integração: "Pensar em movimento não envolve contrários simbólicos, mas está amarrado a uma contínua dinâmica experienciada qualitativamente, na qual possibilidades de movimento surgem e dissolvem-se." (SHEETS-JOHNSTONE, 2009, p. 5).

O corpo em primeira pessoa dialoga com a perspectiva corporal de Laban e com a ação da imagem e da imaginação de Bachelard. Diz Sheets-Johnstone:

É um corpo ao qual não falta realidade biológica, mas um corpo cuja realidade biológica não é nem separável nem uma dimensão em terceira pessoa de sua presença vivida e viva. [...] Precisamos reformar a noção implícita na questão de que o corpo é algo distinto de nós. (Ibidem, p. 20).

Um dos assuntos em que mais se encontram paralelos e analogias entre arquitetura e dança é a relação interior-exterior. $\mathrm{Na}$ arquitetura a transição do espaço externo para o interno e vice-versa é uma das vivências mais marcantes para o usuário. Em termos de corpo, é uma das relações mais significativas, de troca direta com o ambiente, presente na respiração, na alimentação, digestão e excreção, na excreção de fluidos, em penetrações das mais diversas ordens por outros corpos vivos ou por objetos. Sheets-Johnstone chama essa relação de "quarta dimensão":

Essa quarta coordenada é diretamente experienciada pelos corpos vivos e de maneiras significantemente básicas, não apenas em termos da diferença experiencial entre prestar atenção à dinâmica sentida do próprio movimento e prestar atenção à sua tridimensionalidade percebida, mas em termos do próprio corpo. (SHEETS-JOHNSTONE, 2009, p. 366). 
Na Análise Laban de Movimento $(L M A)^{6}$ o Tema Inner/Outer (Mais Interno/Mais Externo) "[...] implica num movimento que transita entre gradações aproximando-se e afastando-se de dentro e de fora, mas não os separa em duas extremidades opostas." (FERNANDES, 2016, p. 65). Transitar entre gradações é um entendimento importante porque reconhece que os limites entre essas duas esferas não são tão claros e fixos e de que é um movimento relacional dinâmico, de constante permeabilidade e recíproca interpenetração e troca. Esse foi um assunto bastante explorado em Contraespaço.

Bachelard é um valorizador da imagem e da imaginação. Ele diz que "As imagens não são conceitos. Não se isolam em sua significação. Tendem precisamente a ultrapassar sua significação. A imaginação nesse caso é multifuncional" (BACHELARD, 1990 , p. 2). Bachelard (2008, p. 18) considera a imaginação "como uma potência maior da natureza humana"; "[...] o sujeito transpondo as coisas." (Idem, 1990, p. 2). As significações subjetivas/fenomenológicas da casa e seus lugares e da questão do habitar me tocaram profundamente, por trazer questões da subjetividade, com uma abordagem fenomenológica, da relação do corpo com o ambiente, mais especificamente, seu ambiente de proteção, o ambiente que se habita. Isso me trouxe uma dimensão da arquitetura sobre a qual não houvera lançado atenção no início da pesquisa, trazendo conteúdos não só da experiência presente e objetiva, mas também do inconsciente, das lembranças, dos sonhos e dos arquétipos. Isso me fez perceber que o que me atraiu e tanto me afetou nos prédios de Hadid, além de suas formas inusitadas e da questão da labilidade, tem muito desse componente de devaneio, de sonho, da imagem de um prédio que pode integrar pensamentos, lembranças e sonhos.

Por essa razão, a escolha por trabalhar com

6 Vertente desenvolvida pela discípula de Laban Irmgard Bartenieff (1900-1981), alemã que se fixou nos Estados Unidos, desenvolvendo os Bartenieff Fundamentals ${ }^{\mathrm{TM}} \mathrm{e}$ fundando o Laban/Bartenieff Institute for Movement Studies, na cidade de Nova York. a imaginação espacial, corporal e de movimento foi a mais apropriada, por acolher esse tipo de fluxo criativo de dar vazão às forças em ação nessa relação de ser afetado pela arquitetura de Hadid.

Bachelard (2008, p. 25) encoraja entrar em uma "sintonia poética", no tom do devaneio. Ele chama a atenção para os valores oníricos que existem paralelamente aos valores objetivos. Trago-os para a arquitetura hadidiana. Alinho essa a outras dimensões de se olhar e se pensar sua obra e para aproximar a sua arquitetura à dança. Aproximar e não traduzir; aproximar para transformar.

Bachelard tem em alto grau a importância das imagens e o que elas podem engatilhar de experiências subjetivas, mas não menos reais. "Todas as imagens são boas desde que saibamos nos servir delas" (Ibidem, p. 46). Esse poderia ser o "mantra" de minha pesquisa com Hadid. "Quantos valores difusos poderíamos concentrar se vivêssemos, com toda a sinceridade, as imagens dos nossos devaneios" (Ibidem, p. 48). E esse poderia ser o convite reiterado para trabalhar com a imaginação corporal, espacial e de movimento.

Bachelard traz ainda a noção de "espacialidade poética", que vai ao encontro da imaginação espacial de Laban, relacionando espaço e intimidade e trabalhando uma expansão que tem como raio desde a intimidade profunda até a expansão infinita (e vice-versa): "Dar seu espaço poético a um objeto é dar-lhe mais espaço do que aquele que ele tem objetivamente, ou melhor dizendo, é seguir a expansão de seu espaço íntimo." (BACHELARD, 2008, p. 206).

Chamei a interligação de ideias de Laban, Sheets-Johnstone e Bachelard de conceitos amalgamadores da pesquisa, que se entremearam no corpo dançante no processo de Contraespaço e nos desdobramentos que dele advieram. 


\section{O processo de Contraespaço} e seus desdobramentos

Espaço positivo e negativo, contraespaços, absorção de contrastes, camadas físicas e de significados e transformação são idiossincraticamente tratados por Hadid. Trouxe esses e outros elementos para a criação em dança, trabalhando com a imaginação espacial, corporal e de movimento.

Escolhi a palavra "contraespaço" para batizar a pesquisa, motivado por uma citação do crítico e curador de arte Germano Celant (2008, p. 19), descrevendo uma das obras de Hadid:

Projetando para fora [do conjunto monolítico do planejamento urbano da Alemanha], estão protuberâncias e calços de espaço negativo e positivo, articulações triangulares $\mathrm{e}$ elípticas que se insinuam no tecido urbano, atravessando sua linearidade e tornando-se contraespaços - magmas tecnológicos multiformes que, em sua desunidade, absorvem todos os contrastes e transformam-se, como coloca Tatlin, em uma "unidade rica em iniciativa". (CELANT, 2008, p. 19, grifo meu).

Essa palavra me deu a sensação de criação de novos espaços a partir dos já existentes à nossa volta.

Assim como obras arquitetônicas, seja em imagens ou in loco, palavras e frases também sugestionaram estímulos visuais e cinestésicos, que entraram no Anel de Moebius da pesquisa junto com os demais elementos. Conforme o escritor Italo Calvino:

Mesmo quando lemos o livro científico mais técnico ou o mais abstrato dos livros de filosofia, podemos encontrar uma frase que inesperadamente serve de estímulo à fantasia figurativa. Encontramos aí um destes casos em que a imagem é determinada por um texto escrito preexistente (uma página ou uma simples frase com a qual me defronto na leitura), dele se podendo extrair um desenrolar fantástico tanto no espírito do texto de partida quanto numa direção completamente autônoma. (CALVINO, 1990, p. 105).
Identifico-me com Calvino em como processos criativos se valem de diversos canais, interrelações e agenciamentos, e aplico à dança como esses canais podem ativar a imaginação espacial, corporal e de movimento. Assim foi com o termo "contraespaço" e com vários outros termos, expressões e frases.

O processo de Contraespaço teve duração de 14 meses, com duas apresentações públicas em forma de ensaios abertos, e foi desenvolvido com os/as bailarinos/as Jefferson Figueirêdo, Juliana Siqueira, Orunmillá Santana e Stefany Ribeiro. Partindo de leituras e assistência a vídeos e documentários sobre Hadid, visualização de suas obras, desenhos, plantas, móveis e objetos e leituras de outros autores, listei cinco Proposições para o trabalho como um todo e 22 Propostas para exploração e improvisação. Foram nossas plataformas de partida no processo.

As Propostas para exploração e improvisação são enunciados de tarefas e exercícios para exploração e improvisação. Vieram de várias fontes e meios de expressão: imagens de obras arquitetônicas; imagens da caligrafia árabe; descrições verbais de Hadid e outros autores de características de obras suas; citações de autores cujos conceitos, ideias e noções me chamaram a atenção pela imagem que suscitam ou pelo que as próprias palavras apresentam como potencialidade para a dança. Já as Proposições para o trabalho como um todo são elementos que funcionam como sugestão de rumo ou comportamento para o todo, no sentido da estruturação ou de sugestão de atmosferas. Devido à limitação de espaço, enumero apenas alguns itens de cada lista, a título de ilustração.

Algumas das Propostas para improvisação e exploração foram:

- "identificar protuberâncias e calços de espaço negativo e positivo que o corpo faz em sua interface com o espaço; transformar os côncavos em convexos e vice-versa";

- $\quad$ "exploração do design de obras arquitetônicas de Hadid, perguntando: 'Que forças regem cada um desses prédios?'; 'No corpo: que vontade de torção, de expansão acontecem para a formação dessas obras?'”; 
- $\quad$ "exploração do paramétrico ${ }^{7}$ - um ponto que afeta o todo".

Algumas das Proposições para o trabalho como um todo foram:

- $\quad$ "uma multiformidade que absorve os contrastes e o transformam";

- "uma circularidade em espiral que abarca e transforma os opostos";

- "organicidade na geração e estruturação de material".

As Propostas para improvisação e exploração foram disparadores iniciais sobre cujo desenvolvimento não havia nenhuma previsão nem controle. Tratou-se de nosso trabalho de campo, um campo criativo, no qual não apenas observamos participativamente, mas, antes disso, nós o criamos. Essa é uma das facetas da PaR.

Tenho experimentado e desenvolvido uma metodologia coreográfica ao longo de 20 anos, resultado de meus estudos em dança, de observação e estudo dos processos de meus coreógrafos/as-referência ${ }^{8}$ e de minha própria prática em dança. Engloba três fases. Na primeira, procuro exaurir possibilidades de exploração e improvisação de aspectos particulares do tema geral escolhido, registrando tudo em vídeo, para consulta e análise posterior. Na segunda, seleciono trechos desse material bruto para manipulações. Na terceira, testo formas de composição e estruturação com o material transformado da segunda fase até sua maturação final (ou provisória). Essas fases não têm uma separação clara ou um andamento programado. Por exemplo, impulsos exploratórios podem se infiltrar em um momento de manipulação, assim como ideias para estruturação podem aparecer já em momentos exploratórios iniciais.

7 Técnica desenvolvida pelo escritório de Hadid, inspirada em sistemas orgânicos e inorgânicos, que consiste em um estímulo em uma parte determinada afetar o todo. (SCHUMACHER, 2008).

80 brasileiro Airton Tenório, a alemã Pina Bausch, os norte-americanos William Forsythe e Meg Stuart, as britânicas Siobhan Davies e Rosemary Butcher e o australiano Lloyd Newson (DV8 Physical Theatre).
Para Contraespaço propus seguir essa metodologia, mas, ao mesmo tempo, quis confrontá-la, como se em alguns momentos pudesse olhar o processo de fora, ver o que aconteceu de uma forma nova para mim e permanecer aberto a desvios, vontades e intuições. O plano inicial eram as listas das Proposições e das Propostas. Mas, no decorrer do processo, tudo poderia acontecer - e eu quis que acontecesse.

Documentei todas as atividades e impressões de todas as fases em um diário de bordo e registrei em vídeo o máximo que pude. Na primeira fase, trabalhamos cada exercício de exploração e improvisação (Figura 1) como se fosse uma escrita automática, ou seja, seguindo ininterruptamente o fluxo formado pela tríade corpo-movimento-criatividade, até exaurir o tema proposto ou até nos exaurirmos (o que, invariavelmente, acontecia). Um aspecto muito marcante que emergiu foram as modificações de estados corporais. A fluidez de certas movimentações, o cansaço e as dores, as experiências com desequilíbrio (labilidade), variações de respiração, a sensibilidade de superfície e contato com membranas (tanto a nível de visualização interna quanto a sensação externa na experimentação com tecido) e a própria abertura a trabalhar com a imaginação espacial, corporal e de movimento possibilitaram a transiência de estados corporais. Isso nos propiciou diferentes perspectivas em relação a: nossos olhares internos; a sensibilidade alterada de nossas superfícies; modos de friç̧ão entre nossos corpos; habitações reais e imaginadas/ árias de espaços em cena; possibilidades de relações entre nós, de afetar e ser afetado, de desestabilizar e de apoiar, de se deixar levar e de manter os pés bem plantados no chão. Uma nova espécie de conhecimento sobre nós mesmos, nossos corpos e a criatividade que esses estados corporais trouxeram à tona foi o que de mais valioso a primeira fase trouxe. Mesmo que algumas das Propostas para improvisação e exploração não houvessem gerado material interessante, a ponto de ser considerado para a composição de um produto artístico posteriormente, a experiência de tê-las realizado alargou nossas vivências corporais e compôs o fluxo da pesquisa. 
Essa fase gerou uma quantidade massiva de material. A princípio, não soubemos o que fazer com ele. Aqui entra o papel da inteligência do próprio processo, que, em seu encadeamento, apresentou a solução de estruturar esse material, aglutinando-o em módulos de dança autônomos, o que permite ordenamentos diferentes a cada vez.

Figura 1 - Pesquisa em dança Contraespaço: $2^{a}$ Proposta para exploração e improvisação: "modelar o corpo do outro com dobras, entrâncias; o corpo como massa receptiva e transformável". Dançarinos: Jefferson Figueirêdo, Orunmillá Santana, Stefany Ribeiro e Juliana Siqueira.

Câmera automática.

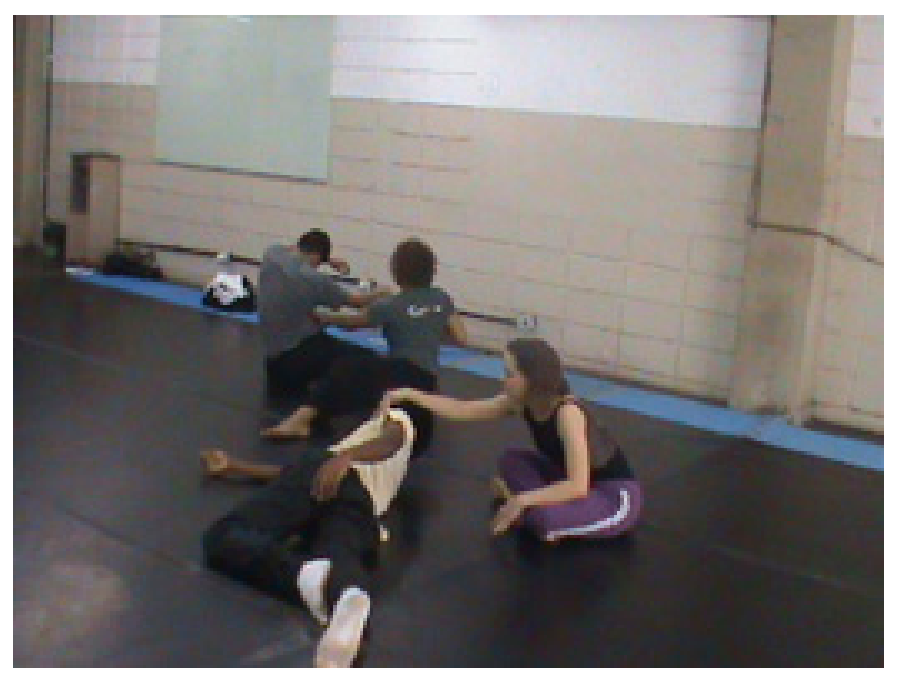

Fonte: Autor.

A segunda fase seria de manipulação do material bruto da primeira, entretanto, as aglutinações que geraram os módulos já constituíram um trabalho de estruturação em um nível micro e, ao mesmo tempo, de manipulação, que eu chamaria de passiva, isto é, deixando que o material se fundisse e encontrasse organicamente as melhores maneiras de se compor em módulos.

Na terceira fase trabalhamos com a estruturação em nível macro, considerando o trabalho como um todo, experimentando possibilidades de ordenamento dos módulos. Passamos a apreciar a prática de verificar quais possíveis sentidos surgiam a cada orde- namento e de como nossos estados corporais eram afetados. Faço uma analogia do uso dos módulos com a coleção de móveis criada por Hadid Seamless Collection $^{9}$, cujos elementos o usuário decide como ordenar pelo espaço e que funções eles podem ter, de assento, de mesa, de apoio, etc., assim, compondo o todo diferentemente a cada reorganização.

Fizemos esse trabalho, primeiramente, na sala de ensaio. Posteriormente, foi surgindo o ímpeto de querer sair e testar como os módulos habitariam diferentes espaços fora do estúdio. Isso não estava programado antecipadamente; foi mais um desdobramento advindo do próprio processo e o acolhemos.

Ao final do processo de Contraespaço, duas vertentes para a feitura de produtos artísticos surgiram. Uma consistiria em explorar ambientes variados de um determinado prédio, propondo uma "habitação" responsiva dos módulos nos espaços. A outra teria o foco na própria estruturação, brincando com o ordenamento dos módulos a cada apresentação, em uma estrutura contínua em um espaço de palco. Decidimos que iríamos concretizar ambas as propostas, em projetos futuros. Intitulamos a primeira proposta Transiterrifluxório e a segunda, Inverso Concreto.

Apresentamos os ensaios abertos em um formato híbrido de apresentação artística e palestra, composto por módulos dançados, projeção de imagens, falas sobre o processo, citações de autores e uma conversa com os espectadores ao final.

Começamos a concretizar Transiterrifluxório (Figura 2) e o estreamos em outubro de 2017. Até o momento, o apresentamos nos seguintes espaços: Igreja da Sé (Olinda-PE), prédio do Teatro Apolo e entorno (Recife-PE), Faculdade de Arquitetura da UFBA (Salvador-BA), casarão do Instituto de Arte Contemporânea do Centro Cultural Benfica (Recife-PE).

Transiterrifluxório nos apresentou vários desafios. Cada espaço apresentou uma diversidade de limitações: de amplitude e configuração espacial; objetos; tipos de chão; significações e codificações prévias. Perguntamos: "como nossa dança pode habitar

9 Pode ser visualizada em: https://www.zaha-hadid.com/ design/seamless-collection/. 
esse espaço?". Respondemos a isso através de uma responsividade (GARRET BROWN, 2013) a essas limitações. Esse termo me parece bastante adequado a uma ideia de maleabilidade e permeabilidade.

Um outro tipo de limitação foram as flutuações de elenco. No processo de Contraespaço éramos cinco. Com a gravidez e maternidade das duas bailarinas, estreamos Transiterrifluxório com os três bailarinos. Em seguida, as duas bailarinas voltaram e um dos bailarinos saiu. A atual formação tem sido: Cláudio, Jefferson, Juliana e Stefany.

A essas limitações ou contingências, o trabalho se mostrou quão maleável e inteligente ele pode ser, como um ser vivo que vai se adaptando às contingências de seu ambiente para sobreviver, conforme fala Sheets-Johnstone (2009) sobre a sensibilidade de superfícies e da inteligência cinética e cinestésica das formas animadas.

Figura 2 - Transiterrifluxório. Instituto de Arte Contemporânea - Centro Cultural Benfica. RecifePE, 13 de setembro de 2019. Dançarinos: Stefany Ribeiro, Juliana Siqueira, Autor e Jefferson Figueirêdo.

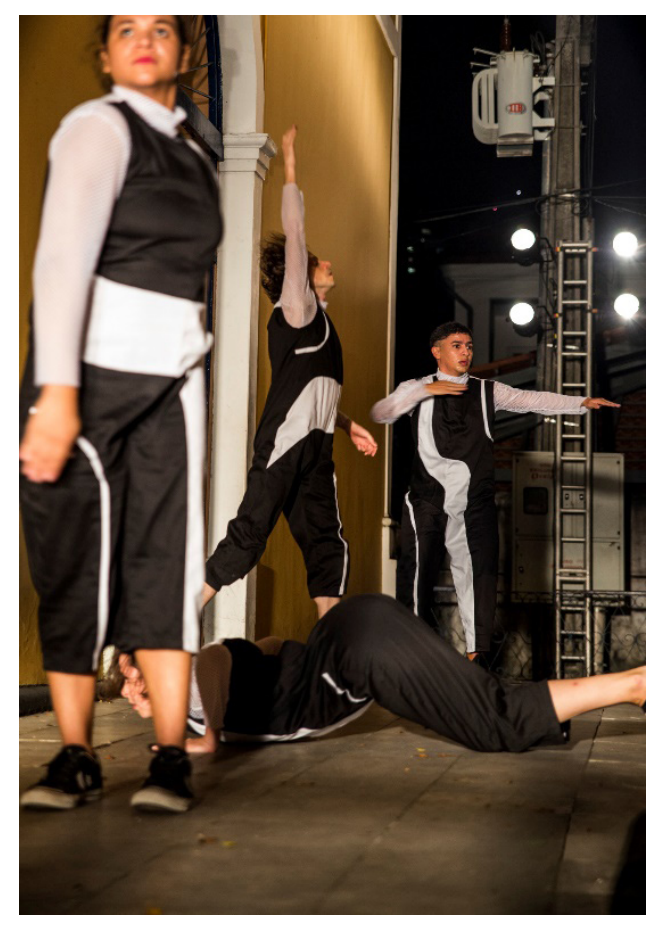

Fonte: Fotógrafo: Rogério Alves
Os espectadores são integrantes fundamentais em Transiterrifluxório. Nas conversas pós espetáculo tenho comentado que há um tripé formado pelo espaço onde apresentamos, pela dança dançada por nós e pelos espectadores que o testemunham. É esse tripé que dá um sentido (ou sentidos) ao espetáculo, naquele espaçotempo no qual ocorre a apresentação. Precisamos da cumplicidade dos espectadores ao longo da itinerância pelos vários ambientes para que a dança aconteça e nunca há uma garantia de já tê-la de antemão; precisamos conquistá-la a cada vez.

Para Inverso Concreto a intenção é apresentá-lo em espaço de palco convencional, privilegiando a faceta do reordenamento da estruturação a cada apresentação. Isso agregará uma característica de pesquisa à própria apresentação e série de apresentações, pois, pela nossa experiência ao longo do processo de Contraespaço, novas significações tendem a aflorar a cada ordenamento e estaremos atentos e curiosos para vivenciá-las e registrá-las. Trabalharemos com os módulos já existentes, mas também desenvolveremos novos, a partir do material bruto ainda não utilizado do banco. Iniciamos o processo de criação e produção em novembro de 2019; precisamos suspendê-lo desde março de 2020, devido à disseminação da pandemia da Covid-19. Tivemos a chance de já desenvolver um novo módulo - a partir do material gerado pelas explorações inspiradas pelo prédio do Phaeno Science Center -, que tem se mostrado instigante, cheio de equilíbrios precários, labilidades e desequilíbrios, individualmente e provocados e assistidos pelo/s outro/s. Pesquisaremos sonoridades para acompanhar cada módulo, que consistirão em alguns dos sons já utilizados em Transiterrifluxório, experimentando justaposições e manipulações, assim como novos elementos. Também terão uma característica de intercambialidade, podendo ser trocada a ordem e as justaposições o quanto desejarmos. Também exploraremos as projeções de vídeos utilizadas em Transiterrifluxório; pretendemos testar variadas possibilidades de configuração junto à cenografia. Quanto a esta, ainda está para acontecer um diálogo entre o grupo e a/o ce- 
nógrafa/o, que resultará na idealização e feitura dos elementos visuais no palco. Em suma, Inverso Concreto está em pleno processo de devir (e suspensão).

\section{Conclusão}

Expus a série de interrelações tecidas no processo da criação-investigação em dança Contraespaço, inspirada pela obra da arquiteta Zaha Hadid. Uma posição político-academicamente determinante foi colocar a dança como motor da própria pesquisa e como articuladora entre as áreas da dança, arquitetura, filosofia e artes visuais. A pesquisa foi realizada a partir de uma perspectiva coreológica, o que significa que teorias de Laban constituíram a âncora principal que mobilizou as interrelações entre áreas e interligações com outros autores, principalmente, Bachelard e Sheets-Johnstone, basilares para poder ter trabalhado com os conceitos de imaginação espacial, corporal e de movimento, no nível do devaneio e das transformações.

Coloquei o Anel de Moebius como representação imagética da pesquisa, cujos elementos estiveram em movimento e em transformação, ativados pelo corpo dançante criativo. Isso esteve em consonância com a $\mathrm{PaR}$, que coloca o fazer artístico como o motor da pesquisa, trazendo todas as imprevisibilidades, descobertas e invenções em potencial que um processo de criação em dança pode trazer. Investimos na própria inteligência do processo e nas forças colocadas em ação.

Testemunhamos e vivenciamos a potência articuladora, criativa e de geração de conhecimento do corpo dançante criativo. $E$ também nos certificamos de quão potentes as teorias de Laban ainda são e das conversas possíveis que podem ter com outros autores e outros campos do saber.

\section{Referências}

BACHELARD, Gaston. A terra e os devaneios do repouso. Tradução de Paulo Neves da Silva - $1^{\text {a }}$ ed. São Paulo: Martins Fontes, 1990.
. A poética do espaço. Tradução de Antônio de Pádua Danesi - $2^{a}$ ed. - São Paulo: Martins Fontes, 2008.

BONENFENT, Yvon. A portrait of the current state of PaR: defining an (in)discipline. In: BOYCE-TILLMAN, June. (Ed.). PaR for the Course: issues involved in the development of practice-based doctorates in the Performing Arts. Winchester: The Higher Education Academy Arts and Humanities, 2012.

BOYARSKY, Alvin. Interview: Alvin Boyarsky talks with Zaha Hadid. In: CELANT, Germano; RAMíREZ-MONTAGUT, Mónica (org.). Zaha Hadid. Catálogo de exposição do Guggenheim Museum, New York. New York: Guggenheim Museum Publications, 2008.

CALVINO, Italo. Seis propostas para o próximo milênio. São Paulo: Companhia das Letras, 1990.

CELANT, Germano. Zaha Hadid: adventure in architecture. In: CELANT, Germano; RAMÍREZ-MONTAGUT, Mónica. (Orgs.). Zaha Hadid. Catálogo de exposição do Guggenheim Museum, New York. New York: Guggenheim Museum Publications, 2008, pp. 17-22.

DERRIDA, Jacques. Linguística e gramatologia. In: DERRIDA, Jacques. Gramatologia. São Paulo: Perspectiva, 2006.

FERNANDES, Ciane. O corpo em movimento: o sistema Laban/Bartenieff na formação e pesquisa em artes cênicas. $2^{\mathrm{a} e d}$. - São Paulo: Annablume, 2006.

Sobre Corpos Vivos: pulsões de uma autenticidade em movimento. Revista Encontro Teatro, $\mathrm{n}^{\circ}$. 03, ano 03. 2016. pp. 55-76.

GARRETT BROWN, Natalie. The Inter-subjective Body. In: REEVE, Sandra. (Ed.). Nine ways of seeing a body; body \& performance. UK: Triarchy Press, 2013. 
HADID, Zaha. Zaha Hadid 2004 laureate acceptance speech. The Pritzker Architecture Prize. 2004. Disponível em: http://www.pritzkerprize.com/2004/ ceremony_speech1. Acesso em: 13 maio 2014.

HASEMAN, Brad. A manifesto for performative research. In: Media International Australia incorporating Culture and policy, theme issue "Practice-led Rese$\operatorname{arch}^{\prime \prime}\left(n^{\circ} .118\right), 2006$, pp. 98-106.

JOHNSON, Philip; WIGLEY, Mark. Deconstructivist architecture. Nova York: MoMA, 1988.

LABAN, Rudolf. Domínio do movimento. São Paulo: Summus, 1978.

Choreutics. Alton: Dance Books, 2011.

PAKES, Anna. Original Embodied Knowledge: the epistemology of the new in dance practice as research. Research in Dance Education, ano 4, vol. 2, 2003, pp. 127-149.

PRESTON-DUNLOP, Valerie. Looking at dances: a choreological perspective on choreography. Londres: Verve, 1998a.

Rudolf Laban: an extraordinary life. Londres:

Dance Books, 1998b.

SCHUMACHER, Patrick. The Skyscraper Revitalized: Differentiation, Interface, Navigation. In: CELANT, Germano; RAMÍREZ-MONTAGUT, Mónica. (Orgs.). Zaha Hadid. Catálogo de exposição do Guggenheim Museum, New York. New York: Guggenheim Museum Publications, 2008, pp. 39-44.

SHEETS-JOHNSTONE, Maxine. The corporeal turn: an interdisciplinary reader. Exeter e Charlottesville: Imprint Academic, 2009.

Recebido: $15 / 06 / 2020$

Aceito: 06/08/2020

Aprovado para publicação: 17/11/2020
Este é um artigo de acesso aberto distribuído sob os termos de uma Licença Crea- tive Commons Atribuição 4.0 Internacional. Disponivel em: <http://creative commons.org/licenses/by/4.0>.

This is an open-access article distributed under the terms of the Creative Commons Attribution License 4.0 International. Available at: <http://creative commons.org/licenses/by/4.0>.

Ce texte en libre accès est placé sous licence Creative Commons Attribution 4.0 International. Disponible sur: <http://creativecommons.org/licenses/by/4.0>. 